\title{
A rare cause of severe Cushing's syndrome
}

\author{
Shamaila Zaman'1, Bijal Patel1', Paul Glynne2, Mark Vanderpump², Ali Alsafi', \\ Sairah Khan', Rashpal Flora', Fausto Palazzo'1 and Florian Wernig' \\ ${ }^{1}$ Hammersmith Hospital, Imperial College Healthcare NHS Trust, London, UK and ${ }^{2}$ The Physicians' Clinic, London, UK
}

Correspondence should be addressed to F Wernig

Email

f.wernig@imperial.ac.uk

\section{Summary}

Ectopic adrenocorticotropic hormone (ACTH) production is an uncommon cause of Cushing's syndrome and, rarely, the source can be a phaeochromocytoma. A 55-year-old man presented following an episode of presumed gastroenteritis with vomiting and general malaise. Further episodes of diarrhoea, joint pains and palpitations followed. On examination, he was hypertensive with no clinical features to suggest hypercortisolaemia. He was subsequently found to have raised plasma normetanephrines of $3.98 \mathrm{nmol} / \mathrm{L}(\mathrm{NR}<0.71)$ and metanephrines of $0.69 \mathrm{nmol} / \mathrm{L}(\mathrm{NR}<0.36)$. An adrenal CT showed a $3.8 \mathrm{~cm}$ right adrenal nodule, which was not MIBG-avid but was clinically and biochemically consistent with a phaeochromocytoma. He was started on alpha blockade and referred for right adrenalectomy. Four weeks later, on the day of admission for adrenalectomy, profound hypokalaemia was noted (serum potassium $2.0 \mathrm{mmol} / \mathrm{L}$ ) with non-specific ST-segment ECG changes. He was also diagnosed with new-onset diabetes mellitus (capillary blood glucose of $28 \mathrm{mmol} / \mathrm{L}$ ). He reported to have gained weight and his skin had become darker over the course of the last 4 weeks. Given these findings, he underwent overnight dexamethasone suppression testing, which showed a non-suppressed serum cortisol of $1099 \mathrm{nmol} / \mathrm{L}$. Baseline serum ACTH was $273 \mathrm{ng} / \mathrm{L}$. A preliminary diagnosis of ectopic ACTH secretion from the known right-sided phaeochromocytoma was made and he was started on metyrapone and insulin. Surgery was postponed for 4 weeks. Following uncomplicated laparoscopic adrenalectomy, the patient recovered with full resolution of symptoms.

\section{Learning points:}

- Phaeochromocytomas are a rare source of ectopic ACTH secretion. A high clinical index of suspicion is therefore required to make the diagnosis.

- Ectopic ACTH secretion from a phaeochromocytoma can rapidly progress to severe Cushing's syndrome, thus complicating tumour removal.

- Removal of the primary tumour often leads to full recovery.

- The limited literature suggests that the presence of ectopic Cushing's syndrome does not appear to have any longterm prognostic implications.

\section{Background}

Ectopic adrenocorticotropic hormone (ACTH) production is a rare cause of Cushing's syndrome and is usually seen in the context of small cell lung cancer, bronchial carcinoid or medullary thyroid cancer (1). Phaeochromocytoma is rarely associated with ectopic ACTH production (2). We present a case of phaeochromocytoma and rapidly progressing Cushing's syndrome due to ectopic ACTH production from the tumour.

\section{Case presentation}

A 55-year-old man presented to a general physician following an episode of presumed gastroenteritis with vomiting and general malaise. Further episodes of diarrhoea, joint pains, sweating and palpitations followed. He described having a 'fizzing sensation' and felt hyperactive. He also developed a new tremor. He has had mild hypertension for a number of years, but a recent significant increase in blood pressure following (c) 2020 The authors https://edm.bioscientifica.com/ Published by Bioscientifica Ltd 
Table 1 Laboratory results at the time of diagnosis of Pheochromocytoma.

Haemoglobin

CRP

Sodium

Potassium

Creatinine

Plasma normetanephrines (NR <0.71)

Plasma metanephrines (NR $<0.36)$

TSH

FT4

Random Glucose
$150 \mathrm{~g} / \mathrm{dL}$

$0.6 \mathrm{mg} / \mathrm{L}$

$142 \mathrm{mmol} / \mathrm{L}$

$3.8 \mathrm{mmol} / \mathrm{L}$

$63 \mu \mathrm{mol} / \mathrm{L}$

$3.98 \mathrm{nmolL}$

$0.69 \mathrm{nmol} / \mathrm{L}$

$1.13 \mu / L$

$19.5 \mathrm{pmol} / \mathrm{L}$

$5.8 \mathrm{mmol} / \mathrm{L}$

the episode of presumed gastroenteritis prompted a referral to a cardiologist who started amlodipine. His past medical history included hyperlipidaemia, shingles and prostatitis. He was an ex-smoker and his alcohol intake was non-significant. His family history revealed that his mother died of lymphoma.

On examination, he was hypertensive with a blood pressure of $200 / 100 \mathrm{mmHg}$. His heart rate was 80 beats per minute with multiple ectopic beats. His weight was stable at $81 \mathrm{~kg}$, and his BMI was $24.7 \mathrm{~kg} / \mathrm{m}^{2}$. There were no clinical features suggestive of hypercortisolaemia. A differential diagnosis of viral infection, thyrotoxicosis or phaeochromocytoma was made. Investigations revealed significantly raised plasma normetanephrines 3.98 $\mathrm{nmol} / \mathrm{L}(\mathrm{NR}<0.71)$ and metanephrines $0.69 \mathrm{nmol} / \mathrm{L}$ (NR $<0.36$; Table 1).

An adrenal CT showed a right $3.8 \mathrm{~cm}$ heterogenous adrenal mass with central areas of low density suggestive of necrosis. The pre-contrast Hounsfield Units were 25. In addition, there was evidence of bilateral adrenal hyperplasia (Fig. 1). Interestingly, the right adrenal nodule was not found to be MIBG avid (Fig. 2). A diagnosis of phaeochromocytoma was made on the basis of clinical symptoms, biochemical evidence of catecholamine excess and the appearance of the adrenal mass on CT. Phenoxybenzamine and later propranolol were commenced. A referral for right adrenalectomy was made.

Six weeks later, the patient was admitted for an elective right adrenalectomy. On admission, profound hypokalaemia was noted (serum potassium: $2.0 \mathrm{mmol} / \mathrm{L}$ ), with non-specific ST-segment ECG changes and left ventricular hypertrophy by voltage criteria (Fig. 3). Calcium and vitamin D levels were found to be low (Table 2). He was also diagnosed with new onset diabetes mellitus (capillary blood glucose: $28 \mathrm{mmol} / \mathrm{L}$ ) and reported to have gained $4 \mathrm{~kg}$ of weight over the last 8 weeks. His skin had become darker over the course of the last 4 weeks.
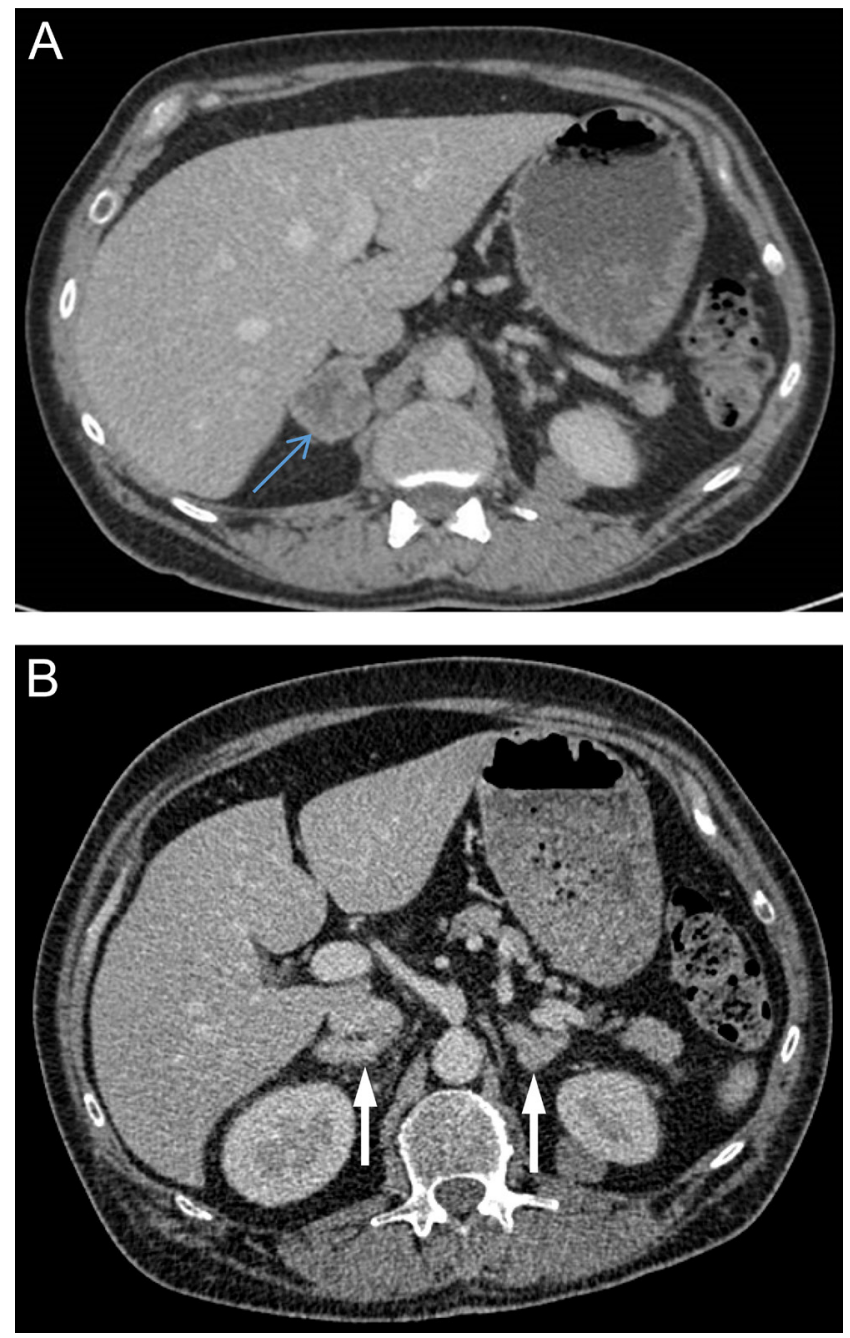

Figure 1

CT of the upper abdomen demonstrating (A) a right adrenal mass (blue arrow) and (B) bilateral adrenal hyperplasia (white arrows).

\section{Investigation}

An overnight dexamethasone suppression test confirmed non-suppressible elevated serum cortisol of $1099 \mathrm{nmol} / \mathrm{L}$. Baseline ACTH was $273 \mathrm{ng} / \mathrm{L}$.

\section{Treatment}

A preliminary diagnosis of ectopic ACTH secretion from the known right-sided phaeochromocytoma was made, and he was started on the 11b-hydroxylase inhibitor metyrapone to control the hypercortisolaemia. Blood glucose was lowered with both i.v. and s.c. insulin, and hypokalaemia was controlled with i.v. and oral potassium supplementation. High-dose vitamin D replacement was commenced. In addition, he was also started on prophylactic oral anti-coagulation therapy 


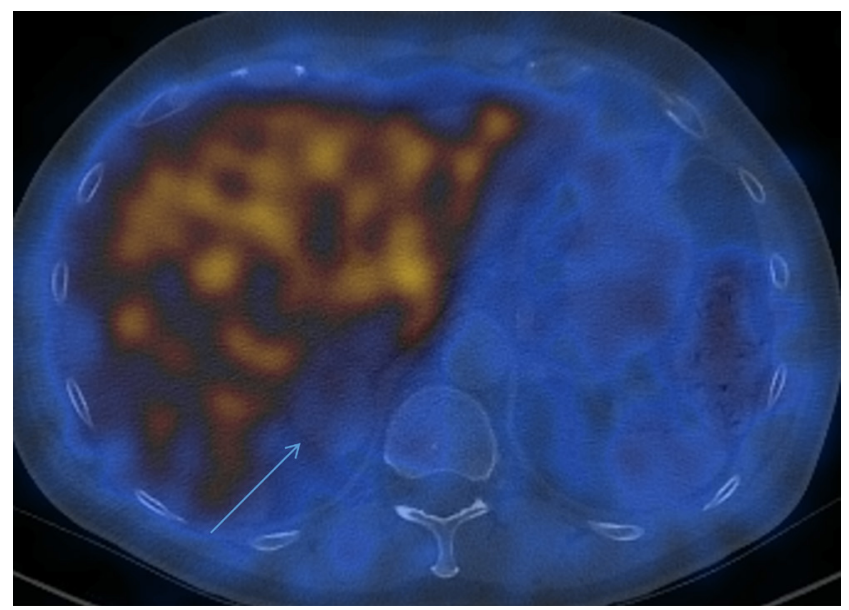

Figure 2

I-123 MIBG: No MIBG uptake in the right adrenal mass; heterogenous liver activity within normal limits.

for the prevention of venous thromboembolism and co-trimoxazole for Pneumocystis Carinii pneumonia prevention. Four weeks later, he underwent an uncomplicated laparoscopic right adrenalectomy. Histology was consistent with a phaeocromocytoma with a PASS score of five, and the tumour stained focally positive for ACTH (Fig. 4).

\section{Outcome and follow-up}

Following surgery, the patient made an excellent recovery with full resolution of his symptoms. He was discharged on prednisolone $4 \mathrm{mg}$ once daily for transient adrenal insufficiency, which was fully weaned off 2 months later. Plasma metanephrines fully normalised after surgery. A genetic screen comprising the ten commonest phaeochromocytoma/paraglanglioma susceptibility genes (FH, MAX, RET, SDHA, SDHB, SDHC, SDHD, SDHAF2, TMEM127 and $V H L)$ was negative.

\section{Discussion}

Cushing's syndrome occurs in 0.7-2.4 cases per million population per year (1). The majority (80\%) of cases are ACTH driven, while $20 \%$ of the cases are ACTH independent, where the primary abnormality is in the adrenal gland (3). Around $80 \%$ of ACTH-dependent cases are estimated to arise from the pituitary gland (Cushing's disease) and the remainder is due to ectopic production of ACTH (4).

The number of case reports of ACTH-secreting phaeochromocytomas in the literature remains limited

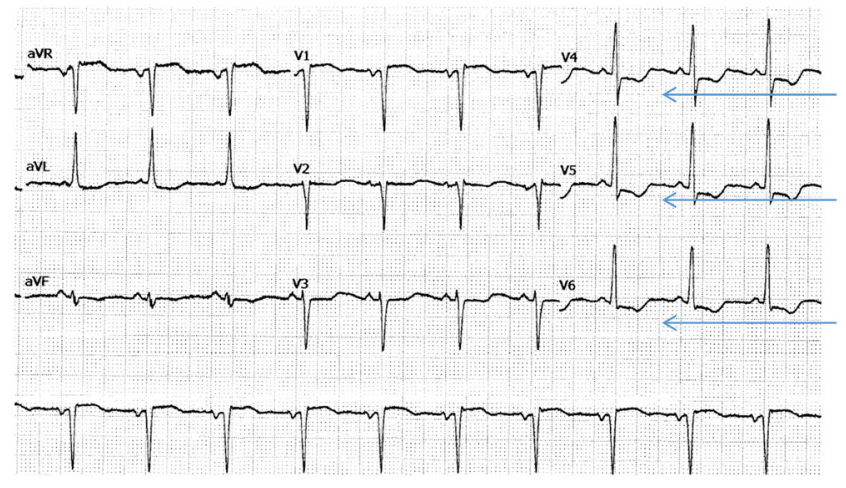

Figure 3

ECG changes with serum potassium of $2.0 \mathrm{mmol} / \mathrm{L}$.

(2). Ballav et al. found that phaeochrmocytomas account for $5.2 \%$ of all cases with ectopic ACTH secretion (5).

Our patient did not have any evidence of Cushing's syndrome when he was first diagnosed with a phaeochromocytoma, but developed severe Cushing's syndrome within weeks. A recent literature review by Gabi et al. confirmed that rapid onset of hypercortisolism appears to be a feature of ACTH-secreting phaeochromocytomas, unlike the insidious onset of other forms of ACTH-dependent Cushing's syndrome (1). Like our patient, the majority of patients had severe Cushingoid symptoms due to the circulating high levels of ACTH and cortisol. Severe hypokalaemia is a feature reported in $95 \%$ of those cases (1). High circulating levels of cortisol exhibit mineralocorticoid activity after

Table 2 Biochemistry at the time of admission for adrenalectomy.

\begin{tabular}{lll}
\hline Tests & Values \\
\cline { 1 - 1 } Cortisol & & \\
$\quad$ Baseline & $1151 \mathrm{nmol} / \mathrm{L}$ \\
Post dexamethasone & $1099 \mathrm{nmol} / \mathrm{L}$ \\
ACTH & $226 \mathrm{ng} / \mathrm{L}$ \\
Plasma metadrenaline (NR <510) & $702 \mathrm{pmol} / \mathrm{L}$ \\
Plasma normetadrenaline (NR <1180) & $2023 \mathrm{pmol} / \mathrm{L}$ \\
DHEAS & $4.6 \mu \mathrm{mol} / \mathrm{L}$ \\
Testosterone & $3.7 \mathrm{nmol} / \mathrm{L}$ \\
Renin & $<0.2$ \\
Aldosterone & $<60 \mathrm{pmol} / \mathrm{L}$ \\
Glucose & $26 \mathrm{mmol} / \mathrm{L}$ \\
pH & 7.55 \\
Bicarbonate & $35 \mathrm{mmol} / \mathrm{L}$ \\
Ketones & $0.2 \mathrm{mmol} / \mathrm{L}$ \\
Potassium & $2.0 \mathrm{mmol} / \mathrm{L}$ \\
Corrected Ca2+ & $2.09 \mathrm{mmol} / \mathrm{mol}$ \\
Vit D & $19 \mathrm{nmol} / \mathrm{L}$ \\
PTH & $17.6 \mathrm{pmol} / \mathrm{L}$ \\
TSH & $2.66 \mu / L$ \\
HbA1C & $78 \mathrm{mmol} / \mathrm{mol}$ \\
\hline
\end{tabular}


A

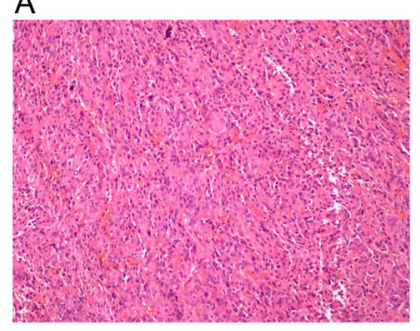

B

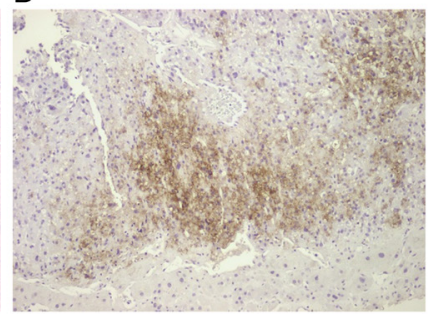

Figure 4

Histological specimens of phaeochromocytoma. (A) Hematoxylin and eosin staining: phaeochromocytoma with adrenocortical hyperplasia. (B) Focally positive ACTH-staining.

saturation of the 11ß-hydroxysteroid dehydrogenase type 2 , the enzyme responsible for its metabolism, thus causing hypokalaemia (6). About $79 \%$ of patients with ectopic secretion of ACTH by a phaeochrmocytoma were noted to have new or worsening hyperglycaemia (1).

In our patient, hypercortisolism due to ectopic ACTH-secretion was suspected due to the presence of profound hypokalaemia and new-onset diabetes mellitus. Recent onset of hypertension, weight gain and increased skin pigmentation further supported the diagnosis. Diagnosis was confirmed by non-suppressible serum cortisol levels on overnight dexamethasone suppression testing and significantly elevated levels of ACTH (273 ng/L). ACTH levels appear to be significantly higher in patients with ectopic ACTH-driven Cushing's syndrome compared to patients with pituitary Cushing's disease. Ballav et al. reported that the 25 patients with ACTH-secreting pheochromocytomas had a mean ACTH level of $344 \mathrm{ng} / \mathrm{L}$ (5).

Therefore, an ectopic source of ACTH can often be differentiated from a pituitary source in the presence of very high ACTH levels and hypokalaemia. Very high and non-suppressible cortisol levels further support the diagnosis of an ectopic source. Petrosal sinus sampling is considered to provide the best diagnostic accuracy to distinguish between pituitary and ectopic ACTH secretion (7). However, significantly elevated cortisol levels in the context of ectopic ACTH secretion often necessitate urgent cortisol-lowering treatment before petrosal sinus sampling can be carried out like in our patient. Rarely, the ectopically-secreted hormone can be CRF, with ACTH being secondarily secreted eutopically from the pituitary gland, potentially resulting in false localization on petrosal sinus sampling. Such tumours will have negative ACTH staining, but positive CRH staining (8).

There is an urgent clinical need to commence cortisol-lowering treatment, as such patients are at a high risk of developing complications such as venous thromboembolism and (opportunistic) infections (5, 9). Therefore, our patient was started on prophylactic anticoagulation and antibiotics to reduce those risks.

Most cases are associated with excellent outcomes following adrenalectomy (5). Our patient's clinical symptoms and biochemical abnormalities fully resolved following surgery.

The size of the adrenal lesion, its heterogeneity, presence of necrosis and Hounsfield's units of 24 were not in keeping with an adenoma. The imaging findings, together with the biochemical results, were highly suspicious for a right-sided phaeochromocytoma. Our patient did not undergo an adrenal protocol CT scan and washout characteristics could therefore not be calculated. The combination of clinical presentation, elevated plasma metanephrines and CT appearance were judged to be sufficient to confidently make a diagnosis of phaeochromocytoma even though the adrenal lesion was not MIBG avid. We and others previously demonstrated that a proportion of phaeochromocytomas which are not detected on 123I-MIBG can be demonstrated by using other PET tracers such as ${ }^{68} \mathrm{Gallium}$-DOTATATE or ${ }^{18}$ F-FDOPA $(10,11)$. In our patient's case, it was not felt that additional molecular imaging would have changed management and it was therefore not considered preoperatively.

Genetic testing should be considered in any patient with phaeochromocytoma, as up to $50 \%$ of patients may have a predisposing genetic mutation, especially if there are other suggestive features, such as a family history, multifocal disease or young age (12).

As phaeochromocytomas are adrenal medullary tumours, cortisol hypersecretion is not always routinely excluded preoperatively. However, this case emphasises the importance of considering ectopic ACTH secretion in patients with known phaeochromocytomas when a patient suddenly develops signs and symptoms suggestive of Cushing's syndrome.

\footnotetext{
Patient's perspective

Looking back, my experience falls into five distinct phases: (1.) Before the gastroenteritis, I recall feeling extremely 'wired' - I was working at what felt like a million miles an hour and completing work tasks, that would previously have taken half a day to a day, in under an hour; and this wasn't just related to work, personally I was resolving problems in my head, and planning grand schemes for the house and garden. It is difficult to know how long this period lasted, but it was a number of months, if not longer. (2.) The period following the gastroenteritis and the diagnosis of the phaeochromocytoma - about 4 weeks - was pretty unpleasant. The (apparently) completely disparate symptoms were high blood pressure
} 
(you know things aren't right when your GP looks at the blood pressure monitor and says 'wow, that's high'), lesions on my fingers that wouldn't heal, palpitations at night, the fizzing sensation (which was like sitting in a glass of champagne) and the continuation of the wired feeling. Not knowing whether these symptoms were linked and, if they were, what that meant, was awful. (3.) I recall my main feeling on being informed that I had a phaeochromocytoma was one of overwhelming relief - at last there was an explanation - and it was resolvable! This period lasted until my first admittance to hospital and was the period during which I developed Cushing's. I recall the water retention, the bizarre stretch marks, the pain in my knees and the dislike of having to walk upstairs (which I assumed were connected and were particularly unpleasant), the gradual weight gain and the darkening of the skin (which I put down to the lovely weather at the time). But I assumed they were side effects of the drugs I was on. (4.) On my first admission to hospital and then being quickly moved to the cardiac ward for monitoring for two days was fairly scary, as was being diagnosed with diabetes. That resulted in a week in hospital, and then another 4 weeks at home waiting for the rearranged operation while undergoing a drug regime. I don't recall a lot about that time but the resolution of the water retention and the diabetes was a relief. (5.) The rearranged operation then took place and my recovery has been very rapid since - the main side-effect being diminishing bouts of anxiety, I presume caused by the discontinuation of the drugs I was taking in the run up to the operation, and/or the disappearance of the effects of the phaeochromocytoma, and/ or the steroid I was on for a short period following the operation. But overall my experience has been extremely positive; I consider myself to be very lucky - the quick diagnosis, the fact that a successful adrenalectomy would resolve everything; even the Cushing's and diabetes was a mild set-back ultimately resolved by the same operation. I was (and remain) extremely grateful to the consultants and surgeons who treated me; the time they took to explain what was happening, why it was happening, the symptoms and their resolution, was fantastic and helped me immeasurably to cope with the whole process. I read up about Cushing after my diagnosis of his syndrome - what an amazing man.

\section{Declaration of interest}

The authors declare that there is no conflict of interest that could be perceived as prejudicing the impartiality of this case report.

\section{Funding}

This case report did not receive any specific grant from any funding agency in the public, commercial or not-for-profit sector.

\section{Patient consent}

Written informed consent has been obtained from the patient for publication of this article and accompanying images.

\section{Author contribution statement}

$P G, M V$ and $F W$ were involved in the clinical care of the patient. A A and S $K$ provided radiological diagnostic support. $R \mathrm{~F}$ performed the pathological examination. F P was the surgeon performing adrenalectomy. S Z, B P and FW wrote the manuscript.

\section{References}

1 Gabi JN, Milhem MM, Tovar YE, Karem ES, Gabi AY \& Khthir RA. Severe Cushing syndrome due to an ACTH-producing pheochromocytoma: a case presentation and review of the literature. Journal of the Endocrine Society 20182 621-630. (https://doi. org/10.1210/js.2018-00086)

2 Kirkby-Bott J, Brunaud L, Mathonet M, Hamoir E, Kraimps JL, Trésallet C, Amar L, Rault A, Henry JF \& Carnaille B. Ectopic hormone-secreting pheochromocytoma: a francophone observational study. World Journal of Surgery 201236 1382-1388. (https://doi.org/10.1007/s00268-012-1488-1)

3 Geva GA, Gross DJ, Mazeh H, Atlan K, Ben-Dov IZ \& Fischer M. Adrenocorticotropic hormone secreting pheochromocytoma underlying glucocorticoid induced pheochromocytoma crisis. Case Reports in Endocrinology 20182018 3963274. (https://doi. org/10.1155/2018/3963274)

4 Newell-Price J, Bertagna X, Grossman AB \& Nieman LK. Cushing's syndrome. Lancet 2006367 1605-1617. (https://doi.org/10.1016/ S0140-6736(06)68699-6)

5 Ballav C, Naziat A, Mihai R, Karavitaki N, Ansorge O \& Grossman AB. Mini-review: pheochromocytomas causing the ectopic ACTH syndrome. Endocrine 201242 69-73. (https://doi.org/10.1007/ s12020-012-9646-7)

6 Quinkler M \& Stewart PM. Hypertension and the cortisol-cortisone shuttle. Journal of Clinical Endocrinology and Metabolism $2003 \mathbf{8 8}$ 2384-2392. (https://doi.org/10.1210/jc.2003-030138)

7 Newell-Price J, Trainer P, Besser M \& Grossman A. The diagnosis and differential diagnosis of Cushing's syndrome and pseudo-Cushing's states. Endocrine Reviews 199819 647-672. (https://doi.org/10.1210/ edrv.19.5.0346)

8 Lois KB, Santhakumar A, Vaikkakara S, Mathew S, Long A, Johnson SJ, Peaston R, Neely RDG, Richardson DL, Graham J, et al. Phaeochromocytoma and ACTH-dependent Cushing's syndrome: tumour crf secretion can mimic pituitary Cushing's disease. Clinical Endocrinology 201684 177-184. (https://doi.org/10.1111/cen.12960)

9 Suarez MG, Stack M, Hinojosa-Amaya JM, Mitchell MD, Varlamov EV, Yedinak CG, Cetas JS, Sheppard B \& Fleseriu M. Hypercoagulability in Cushing syndrome, prevalence of thrombotic events: a large, single-center, retrospective study. Journal of the Endocrine Society 20204 bvz033. (https://doi.org/10.1210/jendso/ bvz033)

10 Maurice JB, Troke R, Win Z, Ramachandran R, Al-Nahhas A, Naji M, Dhillo W, Meeran K, Goldstone AP, Martin NM, et al. A comparison of the performance of (6)(8)Ga DOTATATE PET/ CT and (1)(2)(3)I-MIBG SPECT in the diagnosis and follow-up of phaeochromocytoma and paraganglioma. European Journal of Nuclear Medicine and Molecular Imaging 201239 1266-1270. (https://doi. org/10.1007/s00259-012-2119-7)

11 Rufini V, Treglia G, Castaldi P, Perotti G \& Giordano A. Comparison of metaiodobenzylguanidine scintigraphy with positron emission tomography in the diagnostic work-up of pheochromocytoma and paraganglioma: a systematic review. Quarterly Journal of Nuclear Medicine and Molecular Imaging 201357 122-133.

12 Lenders JW, Duh QY, Eisenhofer G, Gimenez-Roqueplo AP, Grebe SK, Murad MH, Naruse M, Pacak K, Young WF \& Endocrine Society. Pheochromocytoma and paraganglioma: an endocrine society clinical practice guideline. Journal of Clinical Endocrinology and Metabolism 201499 1915-1942. (https://doi.org/10.1210/jc.2014-1498)

Received in final form 21 February 2020

Accepted 26 February 2020 